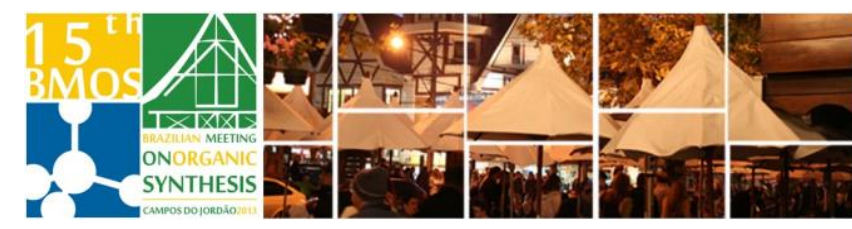

\title{
Michael type reactions mediated by $\mathrm{NbCl}_{5}$.
}

\section{Shirley Muniz Machado Rodrigues* and Gil Valdo José da Silva.}

Dep. de Química, Faculdade de Filosofia, Ciências e Letras de Ribeirão Preto, Universidade de São Paulo, Avenida Bandeirantes $n^{\circ} 3900,14040-901$, Ribeirão Preto-SP, Brazil

*Tel.:+55 (016)-36023879 Fax:+55 (016)-36024838 e-mail: shirleymma@yahoo.com.br

Keywords: Michael addition, niobium pentachloride, silyl enol ethers.

\section{INTRODUCTION}

Over the years researchers have been increasingly interested in the Michael addition [1], because this is one of the most useful reactions for the construction of carbon-carbon bonds, particularly in the synthesis of naturally occurring products and compounds with biological and pharmacological activity [2].

We report here some experimental results involving $\mathrm{NbCl}_{5}$ mediated Michael addition followed by cyclization to bicyclic systems. Bicyclic compounds are traditionally synthesized through Diels Alder reactions. In this work, bicyclo[2.2.2]octan-2-ones have been synthesized using cross-conjugate dienes derived from cyclohexenones [3].

\section{RESULTS AND DISCUSSION}

In the course of our studies on the synthesis of natural products we directed our attention to the reaction between dienol silyl ethers (1-3) with mesityl oxide (4) mediated by $\mathrm{NbCl}_{5}$.

In these reactions we obtained Michael adducts $(\mathbf{5}, \mathbf{6}$ and $\mathbf{8})$ in $15-33 \%$ yield, together with bicyclic products $(\mathbf{7}, \mathbf{9}, 10$ and 11) (Schemes 1 - 3).

Compounds 7, 9, 10 and $\mathbf{1 1}$ are formed by further Robinson type condensation or a second Michael addition (Scheme 4) on the intermediates.
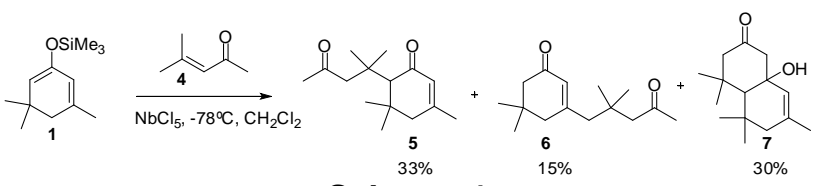

Scheme 1
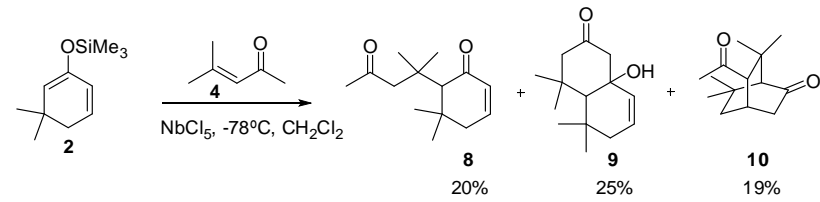
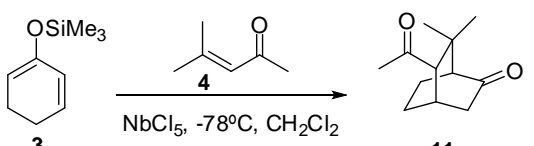

11

Scheme 3

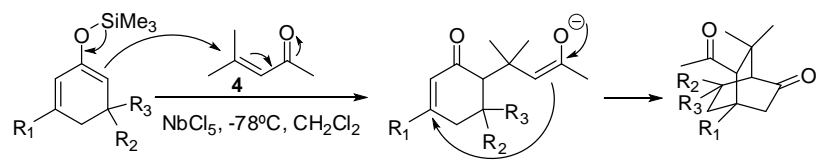

$2 \mathrm{R}_{1}=\mathrm{H}$ and $\mathrm{R}_{2}=\mathrm{R}_{3}=\mathrm{CH}_{3}$ $3 \mathrm{R}_{1}=\mathrm{R}_{2}=\mathrm{R}_{3}=\mathrm{H}$

$10 \mathrm{R}_{1}=\mathrm{H}$ and $\mathrm{R}_{2}=\mathrm{R}_{3}=\mathrm{CH}_{3}$ $11 R_{1}=R_{2}=R_{3}=H$

\section{Scheme 4}

The bicyclic product analogous to $\mathbf{1 0}$ and $\mathbf{1 1}$ is not formed in the reaction with $\mathbf{1}$, possibly due to the sterical hindrance [4] produced by the extra methyl group $\left(R_{1} \neq H\right)$.

\section{CONCLUSION}

In these studies we obtained interesting compounds through Michael type reactions. The double Michael addition is a convenient alternative to Diels-Alder reactions for the preparation of bicyclo[2.2.2]octan-2-ones.

Products of the Robinson type condensation were also obtained.

\section{ACKNOWLEDGEMENTS}

Capes, CNPq, FAPESP.

\section{REFERENCES}

1. Huffman, J. W., Potnis, S. M. and Satish, A. V.; J. Org. Chem., 1985, 4266.

2. Nising, C. F. and Bräse, S.; Chem. Soc. Rev., 2012, 41, 988.

3. a) Nozaki, H.; Yamaguti, T; Ueda, S. and Kondo, K. Tetrahedron, 1968, 24, 1445. b) Scott, J. W.; Vetter, W.; Oberhansli, W. E. and Fürst, A.; Tetrahedron Letters, 1972, 13, 1719

4. White, K. B. and Reusch, W.; Tetrahedron, 1978, 2439.

Scheme 2 